\title{
Research Paper: Investigation of Relationships Between Sensitivity to Reinforcement Traits and Emotion Dysregulation
}

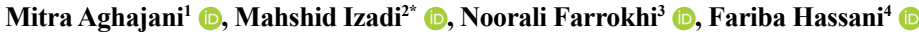

1. Department of Education \& Counseling, Central Tehran Branch, Islamic Azad University, Tehran, Iran.

2. Department of Education and Counseling, Faculty of Psychology and Educational Sciences, Central Tehran Branch, Islamic Azad University, Tehran, Iran.

3. Department of Assessment \& Measurement, Faculty of Psychology and Educational Sciences, Allameh Tabataba'i University, Tehran, Iran.

4. Department of General Psychology, Faculty of Psychology and Educational Sciences, Central Tehran Branch, Islamic Azad University, Tehran, Iran.

\begin{tabular}{|c|c|}
\hline $\begin{array}{l}\text { Use vour decict o s san } \\
\text { and read he article online }\end{array}$ & \\
\hline 口ity & $\begin{array}{l}\text { to Reinforcement Traits and Emotion Dysregulation. Journal of Practice in Clinical Psychology, 9(4), 293-302. https://doi. } \\
\text { org/10.32598/jpcp.9.4.771.2 }\end{array}$ \\
\hline 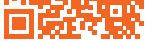 & doi) https://doi.org/10.32598/jpcp.9.4.771.2 \\
\hline
\end{tabular}

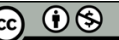

Article info:

Received: 10 Apr 2021

Accepted: 23 Aug 2021

Available Online: 01 Oct 2021

Keywords:

Emotional regulation, Reinforcement, Sensitivity, Student

\section{A B STRACT}

Objective: We investigated the relationship between the Reinforcement Sensitivity Theory (RST) traits and emotion dysregulation signs, including social anxiety, general anxiety, and depression in students.

Methods: A total of 189 students of the public universities in Tehran were selected by convenience sampling and answered the Patient Health Questionnaire-9, Generalized Anxiety Disorder Scale, Social Interaction Anxiety Scale, and Punishment Sensitivity Questionnaire and Reward Sensitivity. Data analysis was done using SPSS v. 26 software by Pearson correlation coefficient and multiple regression analysis.

Results: Pearson correlation coefficient showed a significant relationship between punishment and reward sensitivity and symptoms of emotional dysregulation. Also, multiple regression analysis showed that reward and punishment sensitivity could predict emotion dysregulation.

Conclusion: Punishment hypersensitivity and reward hyposensitivity were higher-order, shared factors for emotion dysregulation signs, including depression, social anxiety, and generalized anxiety. These findings emphasize the effect of behavioral activation as a technique to increase reward pursuit by the individual and suggested that this technique is able to increase reward-seeking and consequently, improve emotional regulation.

* Corresponding Author:

Mahshid Izadi, PhD.

Address: Department of Education and Counseling, Faculty of Psychology and Educational Sciences, Central Tehran Branch, Islamic Azad University,

Tehran, Iran.

Tel: +98 (912) 4593124

E-mail: drizadi.mahshid1452@gmail.com 


\section{Highlights}

- Reward sensitivity can lead to social interaction anxiety.

- Punishment sensitivity can lead to social interaction anxiety.

- Reward sensitivity can lead to generalized anxiety disorder.

- Punishment sensitivity can lead to generalized anxiety disorder.

- Reward sensitivity can lead to depression.

- Punishment sensitivity can lead to depression.

\section{Plain Language Summary}

This study was performed on 195 students of a university in Tehran. The results showed that the intensity of negative and positive emotions as well as sensitivity to punishment and reward can lead to emotional dysfunction, which in this study includes generalized anxiety disorder, social anxiety disorder, and depression.

\section{Introduction}

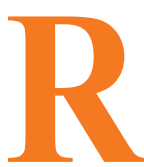

einforcement Sensitivity Theory (RST) (Gray, 1987; Gray \& McNaughton, 2000; Gray, 1970; McNaughton \& Corr, 2004) is one of the most impressive biological theories of contemporary personality. As a result, research in various fields has expanded to areas other than psychopathology (Corr, 2008). According to the main theory, processes related to appetite stimuli are controlled by the Behavioral Approach System (BAS), while the response to aversion stimuli is controlled by a separate and independent Behavioral Inhibition System (BIS) (Corr, 2008). Individual differences in punishment processing, reward processing, and personality are due to different sensitivities of individuals in the performance of BAS and BIS. Those with high BAS tend to demonstrate many cognitive and behavioral approaches to reward promotion and the extroverted personality trait (Corr, 2008; Depue \& Collins, 1999; Gray, 1987). On the other hand, more sensitive BIS has a greater impact on psychological processes and the behaviors associated with punishment and neurosis (Gray, 1970; Smits \& Boeck, 2006).

BIS intends to regulate anxiety; thus, the BIS is directly related to clinical and natural anxiety (Bijttebier, Beck, I., Claes, \& Vandereycken, 2009; Johnson, Turner, \& Iwata, 2003). BIS is strongly directly related to anxiety. BAS plays a lesser role in the experience of anxiety. Most research has shown that anxiety and BAS are generally unrelated or only have a relatively weak relationship with anxiety (Bijttebier et al., 2009). For example, CampbellSills, Liverant, and Brown (2004) concluded that various anxiety disorders are not related to BAS subscales. These findings were true in all types of anxiety disorders; for example, social anxiety disorder (Kashdan \& Roberts, 2006; Kimbrel, Cobb, Mitchell, Hundt, \& Nelson-Gray, 2008; Vervoort, Wolters, Hogendoorn, de Haan, Boer, \& Prins, 2010), obsessive-compulsive disorder (Fullana et al., 2004) as well as anxiety disorders (Johnson et al., 2003). Although anxiety disorders are not largely related to BAS, they are more likely to be associated with similar personality structures, like extroversion (e.g. (Bienvenu, Nestadt, Samuels, Costa, Howard, \& Eaton, 2001; Bienvenu \& Stein, 2003) and emotion. (e.g. (Watson, Gamez, \& Simms, 2005). For instance, Gomez and Francis (2003) assessed 40 patients diagnosed with a Generalized Anxiety Disorder (GAD) and 40 patients with nonclinical control. GAD subjects reported higher neuroticism and lower extraversion scores compared to the controls, and GAD intensity was directly related to anxiety and neuroticism and was inversely related to extraversion. Positive emotion (Brown,Chorpita,\& Barlow , 1998; Watson et al., 2005) and extraversion (Bienvenu et al., 2001; Trull \& Sher, 1994) were inversely related to social anxiety, but they were unrelated to BAS (Kashdan \& Roberts, 2006; Kimbrel et al., 2008; Vervoort et al., 2010).

There is a direct relationship between BIS and generalized anxiety disorder (Campbell-Sills et al., 2004); personality traits characterized by avoidant behavior are as- 
sociated with social anxiety (Andrasik, 2005; Bienvenu $\&$ Stein, 2003) and perhaps BIS has been a precursor to social anxiety (Hirshfeld-Becker, Biederman, Calltharp, S., Rosenbaum, Faraone, \& Rosenbaum, 2003), which can provide indirect support, indicating that BIS is also directly associated with social anxiety. Few studies (Kashdan \& Roberts, 2006; Coplan, Wilson, Frohlick, \& Zelenski, 2006; Kimbrel et al., 2008; Vervoort et al., 2010) have examined the relationship between RST characteristics and social anxiety and indicated that BIS is directly related to social anxiety (Coplan et al., 2006; Kashdan \& Roberts, 2006; Kimbrel et al., 2008; Vervoort et al., 2010). BIS is directly related to different types of anxiety, like social anxiety (Vervoort et al., 2010) and also fear (Hook \& Valentiner, 2002). However, it is not related to BAS (Kashdan \& Roberts, 2006; Kimbrel et al., 2008; Vervoort et al., 2010). Coplan et al. (2006) found a weak inverse relationship between BAS and social anxiety. Some studies have also suggested that social anxiety is inversely related to similar traits, such as extraversion (Bienvenu et al., 2001; EySenck, 1967; Trull \& Sher, 1994), positive emotion (Watson, Clark, \& Carey, 1988), and traits, such as self-control (Chatterjee, Sunitha, Velayudhan, \& Khanna, 1997; Cloninger, 1987; Mörtberg, Bejerot, \& Wistedt, 2007), self-direction (Chatterjee et al., 1997; Mörtberg et al., 2007; Pélissolo et al., 2002) and collaboration (Chatterjee et al., 1997; Marteinsdottir, Tillfors, Furmark, Anderberg, \& Ekselius, 2003; Mörtberg et al., 2007).

The results of various studies have shown that the trend and severity of depression can be predicted by BIS both in the community as well as in clinical samples (Campbell-Sills et al., 2004; Coplan et al., 2006; Kasch, Rottenberg, Arnow, \& Gotlib, 2002; Kimbrel, Nelson-Gray, \& Mitchell, 2007; Pinto-Meza,Caseras, Soler, Puigdemont, Pérez, \& Torrubia, 2006). It has also been shown that BAS is not associated with depression (Johnson et al., 2003), although BAS is expected to be able to predict depressive symptoms inversely. Johnson et al. (2003) suggested that BAS is more associated with anhedonic depression than mixed depression with anxiety. Kimbrel et al. (2008) showed that low BAS was just ahead of the antidote to anhedonic depression, while higher BIS predicts both anxiety and acute depression. BIS can be directly related to depression, although it is primarily associated with anxiety disorders (Kimbrel et al., 2007; Meyer, Johnson, \& Carver 1999; Meyer, Johnson, \& Winters, 2001). The role of BIS in temporary depression has been proven to be greater in long-term depression. In two short-term studies, BAS could predict the severity or course of depressive symptoms, while BIS levels could not be predicted (McFarland, Shankman, Tenke, Brud- er, \& Klein, 2006; Pinto-Meza et al., 2006). Also, both BAS and BIS levels can distinguish the patients from the control group, but only the BAS level can distinguish between the control group and the group with improved depression (Pinto-Meza et al., 2006). In general, BIS is associated with vulnerability to short-term depression and BAS can cause long-term depression (CampbellSills et al., 2004).

According to what was mentioned earlier, we investigated the relationships between RST characteristics, including sensitivity to reward and punishment, and emotional dysregulation signs, including social anxiety, general anxiety, and depression among students.

\section{Materials and Methods}

This study was fundamental research of descriptive and cross-sectional kind based on purpose and data were analyzed by structural equation modeling. We assessed 200 18-year-old and older students studying in one of the public universities in Tehran. They were randomly selected using the convenience sampling method to fill Demographic Questionnaire, Patient Health Questionnaire-9, 7-item Generalized Anxiety Disorder Scale, Social Interaction Anxiety Scale, and Punishment Sensitivity and Reward Sensitivity Questionnaire. We asked the subjects who requested the results to write their e-mail in the questionnaire. The inclusion criteria were students aged 18-50 years old, being students in one of the public universities of Tehran, and informed consent. Distorted questionnaires or no complete answers to the questionnaires were exclusion criteria.

\section{Study tools}

Patient Health Questionnaire-9 (PHQ)-9: PHQ-9 is a self-report instrument that measures the severity of depression And is rated on a Likert scale from zero (never) to three (almost every day). Its English version has acceptable validity and reliability with a sensitivity of $88 \%$ and specificity of $88 \%$ for diagnosing depression. Scores $5,10,15$, and 20 represent mild, moderate, moderately severe, and severe depression, respectively (Kroenke, Spitzer, \& Williams, 2001). It also has acceptable validity on diabetic patients in Iran (Khamseh, Baradaran, Javanbakht, Mirghorbani, Yadollahi, \& Malek, 2011). The internal consistency of PHQ was calculated by Abasi, Kimiaei, Safariyan Tosi, and Abedi (2017) using Cronbach's alpha coefficient and it was confirmed with correlation coefficients of 0.61 to 0.81 . According to the results of exploratory factor analysis, it has four factors. Convergent validity of the PHQ with the psychological 
dimension of SF-36 was computed and indicated a statistically significant correlation between them. Criterion validity indicated a significant negative correlation between the physical dimension SF-36 and PHQ.

Generalized Anxiety Disorder Scale 7-item (GAD7): GAD-7 was designed by Spitzer, Kroenke, Williams, and Löwe (2006) and diagnoses and assesses the severity of generalized anxiety disorder. It has seven questions and another question that evaluates the level of disorder involvement in patients' social, individual, family, and occupational functions. GAD-7 is a 4-statement questionnaire that is scored on a scale from zero to three. Internal validity and test-retest reliability of the scale are 0.92 and 0.83 , respectively. The internal validity of its Iranian version was 0.85 (Naeinian, Shaeiri, Sharif, \& Hadian, 2011). The correlation coefficient obtained by the first and second implementations of the GAD-7 scale was equal to 0.48 . Therefore, it can be said that the short-form scale has an acceptable test- reliability (Naeinian et al., 2011).

Social Interactions Anxiety Scale (SIAS): SIAS was designed by Mattick and Clarke (1998) as a 20-item self-report scale that is rated on a 5-point Likert scale. Its Cronbach's alpha coefficient and test-retest reliability at the 2-week interval were 0.86 and $0.85-0.90$, respectively (Mattick \& Clarke, 1998). The correlation between SIAS and other scales of avoidance of social situations and social interaction fear, and other tools assessing social anxiety was reported as moderate to high (Rodebaugh, Woods, \& Heimberg, 2007). In Iran, its test-retest reliability and Cronbach's alpha coefficient were 0.79 and 0.90 , respectively (Mosarezaee, Tavoli, \& Montazeri, 2020). SIAS measures the severity of social anxiety disorder symptoms. The internal consistency of its Persian version was 0.91 . Also, confirmatory factor analysis showed that its factor structure was valid: RMSEA $=0.04, \mathrm{GFI}=0.94, \mathrm{P}<0.001, \chi^{2}=297.43$, and $\mathrm{df}=149$ (Abasi, Feldman, Farazmand, Pourshahbaz, \& Sarichloo, 2018).

Sensitivity to Punishment and Sensitivity to Reward Questionnaire (SPSRQ): SPSRQ is a 48-item self-report questionnaire that was designed by Torrubia, Avila, Moltó, and Caseras (2001) which can measure individual differences in sensitivity to punishment and reward in individuals. . The respondent receives a score between 1 and 2 for each item and the total score is between 48 and 96. Cronbach's alpha coefficient was reported to be 0.76 and 0.82 for the subscales of reward sensitivity and punishment sensitivity, respectively. An agreement coefficient of $81 \%$ was declared for SPSRQ (Torrubia et al., 2001). The reliability coefficient of 0.74 and 0.70 was reported for the subscales of punishment sensitivity and reward sensitivity, respectively (Goodarzi \& Shameli, 2010). To evaluate punishment sensitivity and reward sensitivity, the latent variable of motivation was used in SPSRQ. The internal consistency of 0.74 and 0.84 was reported for the subscales of safety and reward motivation for its Iranian version, respectively. Confirmatory factor analysis showed that the reward and safety subscales were valid: $\mathrm{RMSEA}=0.03, \mathrm{GFI}=0.96, \mathrm{P}<0.001$, $\mathrm{df}=128, \quad \chi^{2}=196.62$ and $\mathrm{RMSEA}=0.007, \quad \mathrm{GFI}=0.96$, $\mathrm{P}>0.376, \mathrm{df}=219, \chi^{2}=225.20$, respectively (Abasi et al., 2017).

Data analysis: Multiple regression analysis and Pearson product-moment correlation coefficient were used for data analysis using SPSS software version 26.

\section{Results}

Participants in this study were 189 people, of whom $50.8 \%$ were female and $49.2 \%$ were male. Also, $15.9 \%$ of the subjects were married and $81.0 \%$ were single. They aged 18 - 35 years and those with undergraduate education constituted the largest number of participants. Table 1 indicates the demographic characteristics of the participants.

The mean and standard deviation and correlation matrix of study variables are presented in Table 2. Reward sensitivity was significantly and negatively correlated with social anxiety, generalized anxiety, and depression. Also, punishment sensitivity showed a significant positive relationship with generalized anxiety, social anxiety, and depression.

After examining the relationships between variables, multiple regression with simultaneous methods was used to determine the predictivity of sensitivity to reinforcement. Punishment sensitivity and reward sensitivity were assessed by regression analysis of social interaction anxiety to determine the components of punishment and reward sensitivity and accounted for a high percentage of the variance of social interaction anxiety. The results showed that punishment and reward sensitivity could explain $36 \%$ of the variance of social interaction anxiety. Also, the most important predictor according to beta coefficients was the component of reward sensitivity and then sensitivity to punishment. With increasing the sensitivity to punishment, social interaction anxiety is also increased and social interaction anxiety is decreased with increasing sensitivity to reward (Table 3).

The components of punishment sensitivity and reward regressed on general anxiety disorder. The results 
Table 1. Demographic characteristics of the participants

\begin{tabular}{|c|c|c|}
\hline \multicolumn{2}{|c|}{ Variables } & \multirow{2}{*}{$\begin{array}{l}\text { No. (\%) } \\
96(50.8)\end{array}$} \\
\hline & Female & \\
\hline Sex & Male & $93(49.2)$ \\
\hline & Total & 189(100.0) \\
\hline \multirow{4}{*}{ Marital status } & Single & $153(81.0)$ \\
\hline & Married & $30(15.9)$ \\
\hline & Divorced & $3(1.6)$ \\
\hline & Others & $3(1.6)$ \\
\hline \multirow{4}{*}{ Age (y) } & $>20$ & $15(7.9)$ \\
\hline & $20-25$ & 119(63.0) \\
\hline & $25-30$ & $52(27.5)$ \\
\hline & $30-35$ & $3(1.6)$ \\
\hline \multirow{4}{*}{ Education level } & Bachelor & $92(48.7)$ \\
\hline & Master & $70(37.0)$ \\
\hline & $\mathrm{PhD}$ & $27(14.3)$ \\
\hline & Total & 189(100.0) \\
\hline
\end{tabular}

showed that the components of sensitivity to punishment and reward generally explained $39 \%$ of the variance of the generalized anxiety disorder (Table 4). The punishment and reward sensitivity was regressed on depression as well. The results showed that punishment and reward sensitivity could explain $41 \%$ of the variance of depression. The component of punishment directly and the reward component reversely could predict depression (Table 4).

\section{Discussion}

PRACTICE II
CLINICAL PSYCH $\oplus$ LOGY

Our results showed that sensitivity to punishment and reward had a direct effect on symptoms of emotional dysregulation (including generalized anxiety disorder, social anxiety, and depression), which was in line with the results of previous studies (Hong, 2007; Katz, Matanky, Aviram, \& Yovel, 2020; Trew, 2011). Trew (2011) states that just as BAS (equivalent to reward sen-

Table 2. Correlation matrix and Mean \pm SD of the study variables $(n=189)$

\begin{tabular}{|c|c|c|c|c|c|c|}
\hline Raw & Variables & Mean $\pm S D$ & 1 & 2 & 3 & 4 \\
\hline 1 & Reward sensitivity & $11.94 \pm 4.59$ & & & & \\
\hline 2 & Punishment sensitivity & $11.17 \pm 6.23$ & -0.645 & & & \\
\hline 3 & Social anxiety & $27.18 \pm 12.18$ & -0.575 & 0.506 & & \\
\hline 4 & Generalized anxiety & $10.97 \pm 5.67$ & -0.597 & 0.514 & 0.631 & \\
\hline 5 & Depression & $12.05 \pm 7.69$ & -0.614 & 0.526 & 0.733 & 0.832 \\
\hline
\end{tabular}

PRACTICE In PSYCAL $\circledast$ LOGY

Table 3. Results of regression of punishment and reward sensitivity on social interactions anxiety

\begin{tabular}{ccccccccccc}
\hline Variables & b & Std.Error & $\boldsymbol{\beta}$ & $\mathbf{t}$ & Sig. & $\mathbf{F}$ & Sig. & $\mathbf{R}$ & $\mathbf{R}^{2}$ & adj $\mathbf{R}^{2}$ \\
\hline (Constant) & 35.62 & 3.80 & & 9.38 & 0.001 & 52.73 & 0.001 & 0.60 & 0.36 & 0.35 \\
Reward sensitivity & -1.13 & 0.20 & -0.43 & -5.56 & 0.001 & & & & & \\
Punishment sensitivity & 0.45 & 0.15 & 0.23 & 3.01 & 0.001 & & & & \\
\hline
\end{tabular}


Table 4. Results of regression analysis of punishment and reward sensitivity on generalized anxiety disorder

\begin{tabular}{ccccccccccc}
\hline Variables & b & SE & $\boldsymbol{\beta}$ & $\mathbf{t}$ & Sig. & $\mathbf{F}$ & Sig. & $\mathbf{R}$ & $\mathbf{R}^{2}$ & adj $\mathbf{R}^{2}$ \\
\hline (Constant) & 15.44 & 1.74 & & 8.90 & 0.001 & 58.29 & 0.001 & 0.62 & 0.39 & 0.38 \\
Reward sensitivity & -0.56 & 0.09 & -0.46 & -6.05 & 0.001 & & & & & \\
Punishment sensitivity & 0.20 & 0.07 & 0.22 & 2.93 & 0.001 & & & & \\
\hline
\end{tabular}

Table 5. Results of regression analysis of punishment and reward sensitivity on depression

\begin{tabular}{ccccccccccc}
\hline Variables & $\mathbf{b}$ & SE & $\boldsymbol{\beta}$ & $\mathbf{t}$ & Sig. & $\mathbf{F}$ & Sig. & $\mathbf{R}$ & $\mathbf{R}^{2}$ & adj $\mathbf{R}^{2}$ \\
\hline (Constant) & 18.36 & 2.31 & & 7.94 & 0.001 & 63.47 & 0.001 & 0.64 & 0.41 & 0.40 \\
Reward sensitivity & -0.79 & 0.12 & -0.47 & -6.35 & 0.001 & & & & & \\
Punishment sensitivity & 0.27 & 0.09 & 0.22 & 3.01 & 0.001 & & & & \\
\hline
\end{tabular}

sitivity and reinforcement) is associated with positive emotions; thus, it probably is involved in the etiology of depression. In other words, low BAS leads to defective activation and activity orientation, resulting in a decrease in the experience of positive experiences. Low BAS is even a barrier to improving depression and leads to slow recovery in depressed patients (McFarland et al., 2006). On the other hand, Harnett, Loxton and Jackson (2013) showed that BIS (equivalent to sensitivity to threat and punishment) is associated with depression, a finding that is in line with our results o and the research by Campbell-Sills et al. (2004).

A large meta-analysis by Katz et al. (2020) also showed that hypersensitivity to low reinforcement and sensitivity to high punishment predict depression. Overall, Trew (2011), in explaining the relationship between sensitivity to reinforcement and punishment with depression, stated that hypersensitivity BAS and hypersensitivity BIS are likely to combine to prevent the pursuit of goals. This view is consistent with the hypothesis of connected subsystems (JSH) (Corr, 2002) which states that reinforcement-sensitive systems and punishment-sensitive systems, although independent of each other, can in some cases, interact with each other.

In addition, sensitivity to punishment is associated with anxiety outcomes (Cremers \& Roelofs, 2016; Neal \& Gable, 2017). Neal and Gable (2017) stated that the BIS system and sensitivity to punishment are associated with inhibition of goal-oriented behaviors in response to unpleasant stimuli and, consequently, with feelings of anxiety. Sensitivity to high punishment causes the person to constantly pay attention to possible signs of danger and threat and as a result, is always involved in anxiety emotions. Also, behavioral inhibition to reduce the likelihood of punishment leads to reduced participation in social relationships (Fayazi \& Hasani, 2017), relationships which may be accompanied by threats, such as meeting new people, being watched by others, and being judged. As a result, the individual avoids society to avoid these consequences. Reward sensitivity has also been relatively weakly linked to anxiety in previous research (Katz et al., 2020; McNaughton \& Corr, 2004) and it has been suggested that sensitivity has a greater role in reinforcing depression than anxiety. In another model, Watson (2009) concluded that BIS hypersensitivity causes overall vulnerability, while BAS hypersensitivity converts overall vulnerability to depression.

However, in the present study, the correlation coefficient of reward sensitivity with generalized anxiety and social anxiety was almost similar to the correlation coefficient of reward sensitivity with depression and in this respect is inconsistent with recent research and a metaanalysis by Katz et al. (2020). In explaining this finding, the long-term effects of punishment sensitivity in anxiety can be considered so that the continued inactivity of the system sensitive to punishment and threat over time and failure to reduce the activity of this system leads to a kind of burnout and helplessness. As a result, a person's motivation to change and control the environment decreases and he is no longer even able to seek reinforcement and reward. Although this possible explanation is consistent with some previous research, such as a study by Silk, Davis, McMakin, Dahl, and Forbes (2012), which has 
shown that anxious children become adolescents who are depressed, more research is needed in the future.

Our results are consistent with the approach that states that sensitivity to punishment (BIS) is a common cause of depression and anxiety and is responsible for the high comorbidity of depressive and anxiety disorders (Katz et al., 2020; Kessler, Chiu, Demler, \& Walters, 2005). It can be said that the pathology of these two, in the first place, refers to the sensitivity to punishment, threats, and insecurity.

\section{Conclusion}

We found strong support for sensitivity to punishment and reward (Zinbarg \& Yoon, 2008) that may be consistent with the joint subsystems hypothesis (Corr, 2002). Sensitivity to punishment and hypersensitivity to reward as a major and common factor for emotion disorder include depression, social anxiety, and generalized anxiety disorder. These results can improve the understanding of the nature of emotional pathology, and consequently, create more personal and effective therapies. These findings regarding the role of behavioral activation as an approach to enhance the individual's search for reward, suggest that it is able to increase reward-seeking and thus, improve emotion regulation.

The results of the present study should be considered in light of some limitations. It was cross-sectional research and some other longitudinal studies have reported different results. Another limitation was our samples, which makes the results only generalizable to the students. Further studies are suggested using other healthy samples, like adolescents and the elderly, or clinical samples, like cases with major depression, generalized anxiety disorder, or eating disorders. The third limitation of this study was the use of a questionnaire to diagnose depression, generalized anxiety disorder, and social anxiety. Subsequent research should use structured interviews to diagnose these disorders.

\section{Ethical Considerations}

\section{Compliance with ethical guidelines}

All ethical principles are considered in this article. The participants were informed about the purpose of the research and its implementation stages. They were also assured about the confidentiality of their information. They were free to leave the study whenever they wished, and if desired, the research results would be available to them.

\section{Funding}

The paper was extracted from the $\mathrm{PhD}$. dissertation of the first author at the Department of Human Science, Islamic Azad University of Tehran.

\section{Authors' contributions}

All authors equally contributed to preparing this article

\section{Conflict of interest}

The authors declared no conflict of interest.

\section{References}

Abasi, F., Kimiaei, S. A., Safariyan Tosi, M., \& Abedi, M. R (2017). [Psychometric properties of the Persian version of physical health questionnaire (Persain)]. Research in Medicine, 41(4), 275-81. http:/ / pejouhesh.sbmu.ac.ir/article-1-1741-en. html

Abasi, I., Feldman, G., Farazmand, S., Pourshahbaz, A., \& Sarichloo, M. E. (2018). A psychometric evaluation of iranian version of the Responses to Positive Affect (RPA) Questionnaire. Iranian Journal of Psychiatry and Behavioral Sciences, 12(4), e11923. [DOI:10.5812/ijpbs.11923]

Abasi, I., Mohammadkhani, P., Pourshahbaz, A., \& Dolatshahi, B. (2017). The psychometric properties of attentional control scale and its relationship with symptoms of anxiety and depression: A study on Iranian population. Iranian Journal of Psychiatry, 12(2), 109-17. [PMID] [PMCID]

Andrasik, F. (2005). Comprehensive handbook of personality and psychopathology, adult psychopathology. Hoboken: John Wiley \& Sons. https://www.google.com/books/edition/Comprehensive_Handbook_of_Personality_an/6jWdj

Bienvenu, O. J., Nestadt, G., Samuels, J. F., Costa, P. T., Howard, W. T., \& Eaton, W. W. (2001). Phobic, panic, and major depressive disorders and the five-factor model of personality. The Journal of Nervous and Mental Disease, 189(3), 154-61. [DOI:10.1097/00005053-200103000-00003] [PMID]

Bienvenu, O. J., \& Stein, M. B. (2003). Personality and anxiety disorders: A review. Journal of Personality Disorders, 17(2: Special issue), 139-51. [DOI:10.1521/pedi.17.2.139.23991] [PMID]

Bijttebier, P., Beck, I., Claes, L., \& Vandereycken, W. (2009). Gray's reinforcement sensitivity theory as a framework for research on personality-psychopathology associations. Clinical Psychology Review, 29(5), 421-30. [DOI:10.1016/j. cpr.2009.04.002] [PMID]

Brown, T. A., Chorpita, B. F., \& Barlow, D. H. (1998). Structura relationships among dimensions of the DSM-IV anxiety and mood disorders and dimensions of negative affect, positive affect, and autonomic arousal. Journal of Abnormal Psychology, 107(2), 179-92. [DOI:10.1037/0021-843X.86.2.179] [PMID] 
Campbell-Sills, L., Liverant, G. I., \& Brown, T. A. (2004). Psychometric evaluation of the behavioral inhibition/behavioral activation scales in a large sample of outpatients with anxiety and mood disorders. Psychological Assessment, 16(3), 244-54. [DOI:10.1037/1040-3590.16.3.244] [PMID]

Chatterjee, S., Sunitha, T., Velayudhan, A., \& Khanna, S. (1997). An investigation into the psychobiology of social phobia: Personality domains and serotonergic function. Acta Psychiatrica Scandinavica, 95(6), 544-50. [DOI:10.1111/j.1600-0447.1997. tb10144.x] [PMID]

Cloninger, C. R. (1987). A systematic method for clinical description and classification of personality variants: A proposal Archives of General Psychiatry, 44(6), 573-88. [DOI:10.1001/ archpsyc.1987.01800180093014] [PMID]

Coplan, R. J., Wilson, J., Frohlick, S. L., \& Zelenski, J. (2006). A person-oriented analysis of behavioral inhibition and behavioral activation in children. Personality and Individual Differences, 41(5), 917-27. [DOI:10.1016/j.paid.2006.02.019]

Corr, P. J. (2002). JA Gray's reinforcement sensitivity theory: Tests of the joint subsystems hypothesis of anxiety and impulsivity. Personality and Individual Differences, 33(4), 511-32. [DOI:10.1016/S0191-8869(01)00170-2]

Corr, P. J. (2008). The reinforcement sensitivity theory of personality. Cambridge: Cambridge University Press. [DOI:10.1017/ CBO9780511819384]

Cremers, H. R., \& Roelofs, K. (2016). Social anxiety disorder: A critical overview of neurocognitive research. Wiley interdisciplinary reviews. Cognitive Science, 7(4), 218-32. [DOI:10.1002/ wcs.1390] [PMID]

Depue, R. A., \& Collins, P. F. (1999). Neurobiology of the structure of personality: Dopamine, facilitation of incentive motivation, and extraversion. Behavioral and Brain Sciences, 22(3), 491-517. [DOI:10.1017/S0140525X99002046] [PMID]

EySenck, H. J. (1967). The biological basis of personality. New Brunswick: C. C. Thomas. https://www.google.com/books/edition/The_Biological_Basis_of_Personality/unee8oL0Og

Fayazi, M., \& Hasani, J. (2017). Structural relations between brain-behavioral systems, social anxiety, depression and internet addiction: With regard to revised Reinforcement Sensitivity Theory (r-RST). Computers in Human Behavior, 72, 441-8. [DOI:10.1016/j.chb.2017.02.068]

Fullana, M. A., Mataix-Cols, D., Caseras, X., Alonso, P., Menchón, J. M., \& Vallejo, J., et al. (2004). High sensitivity to punishment and low impulsivity in obsessive-compulsive patients with hoarding symptoms. Psychiatry Research, 129(1), 21-7. [DOI:10.1016/j.psychres.2004.02.017] [PMID]

Gomez, R., \& Francis, L. M. (2003). Generalised anxiety disorder: Relationships with Eysenck's, Gray's and Newman's theories. Personality and Individual Differences, 34(1), 3-17. [DOI:10.1016/S0191-8869(02)00020-X]

Goodarzi, M., \& Shameli, L. (2010). [Prediction of identity styles based on sensitivity to reward and punishment (Persian)]. Journal of Applied Psychology, 4(3), 81-95. [DOI:20.1001.1.2008 4331.1389.4.4.2.6]

Gray, J. (1987). The psychology of fear and stress. New York: Cambridge University Press. https://www.google.com/books/ edition/The_Psychology_of_Fear_and_Stress/nww5
Gray, J., \& McNaughton, N. (2000). The neuropsychology of anxiety: An enquiry into the functions of the septohippocampal system. Oxford: Oxford University Press. https:// www.google.com/ books/edition/The_Neuropsychology_of_Anx

Gray, J. A. (1970). The psychophysiological basis of introversion-extraversion. Behaviour Research and Therapy, 8(3), 249-66. [DOI:10.1016/0005-7967(70)90069-0]

Harnett, P. H., Loxton, N. J., \& Jackson, C. J. (2013). Revised reinforcement sensitivity theory: Implications for psychopathology and psychological health. Personality and Individual Differences, 54(3), 432-7. [DOI:10.1016/j.paid.2012.10.019]

Hirshfeld-Becker, D. R., Biederman, J., Calltharp, S., Rosenbaum, E. D., Faraone, S. V., \& Rosenbaum, J. F. (2003). Behavioral inhibition and disinhibition as hypothesized precursors to psychopathology: Implications for pediatric bipolar disorder. Biological Psychiatry, 53(11), 985-99. [DOI:10.1016/S00063223(03)00316-0]

Hong, R. Y. (2007). Worry and rumination: Differential associations with anxious and depressive symptoms and coping behavior. Behaviour Research and Therapy, 45(2), 277-90. [DOI:10.1016/j.brat.2006.03.006] [PMID]

Hook, J. N., \& Valentiner, D. P. (2002). Are specific and generalized social phobias qualitatively distinct? Clinical Psychology: Science and Practice, 9(4), 379-95. [DOI:10.1093/ clipsy.9.4.379]

Johnson, S. L., Turner, R. J., \& Iwata, N. (2003). BIS/BAS levels and psychiatric disorder: An epidemiological study. Journal of Psychopathology and Behavioral Assessment, 25(1), 25-36. [DOI:10.1023/A:1022247919288]

Kasch, K. L., Rottenberg, J., Arnow, B. A., \& Gotlib, I. H. (2002). Behavioral activation and inhibition systems and the severity and course of depression. Journal of Abnormal Psychology, 111(4), 589-97. [DOI:10.1037/0021-843X.111.4.589] [PMID]

Kashdan, T. B., \& Roberts, J. E. (2006). Affective outcomes in superficial and intimate interactions: Roles of social anxiety and curiosity. Journal of Research in Personality, 40(2), 140-67. [DOI:10.1016/j.jrp.2004.10.005]

Katz, B., Matanky, K., Aviram, G., \& Yovel, I. (2020). Reinforcement sensitivity, depression and anxiety: A meta-analysis and meta-analytic structural equation model. Clinical Psychology Review, 77, 101842. [DOI:10.1016/j.cpr.2020.101842] [PMID]

Kessler, R. C., Chiu, W. T., Demler, O., \& Walters, E. E. (2005) Prevalence, severity, and comorbidity of 12-month DSM-IV disorders in the National Comorbidity Survey Replication. Archives of General Psychiatry, 62(6), 617-27. [DOI:10.1001/ archpsyc.62.6.617] [PMCID]

Khamseh, M. E., Baradaran, H. R., Javanbakht, A., Mirghorbani, M., Yadollahi, Z., \& Malek, M. (2011). Comparison of the CES$\mathrm{D}$ and PHQ-9 depression scales in people with type 2 diabetes in Tehran, Iran. BMC Psychiatry, 11, 61. [DOI:10.1186/1471244X-11-61] [PMID] [PMCID]

Kimbrel, N. A., Cobb, A. R., Mitchell, J. T., Hundt, N. E., \& Nelson-Gray, R. O. (2008). Sensitivity to punishment and low maternal care account for the link between bulimic and social anxiety symptomology. Eating Behaviors, 9(2), 210-7. [DOI:10.1016/j.eatbeh.2007.09.005] [PMID]

Kimbrel, N. A., Nelson-Gray, R. O., \& Mitchell, J. T. (2007). Reinforcement sensitivity and maternal style as predictors of 
psychopathology. Personality and Individual Differences, 42(6), 1139-49. [DOI:10.1016/j.paid.2006.06.028]

Kroenke, K., Spitzer, R. L., \& Williams, J. B. (2001). The PHQ-9: Validity of a brief depression severity measure. Journal of General Internal Medicine, 16(9), 606-13. [DOI:10.1046/j.15251497.2001.016009606.x] [PMID] [PMCID]

Marteinsdottir, I., Tillfors, M., Furmark, T., Anderberg, U. M. \& Ekselius, L. (2003). Personality dimensions measured by the Temperament and Character Inventory (TCI) in subjects with social phobia. Nordic Journal of Psychiatry, 57(1), 29-35. [DOI:10.1080/08039480310000239] [PMID]

Mattick, R. P., \& Clarke, J. C. (1998). Development and validation of measures of social phobia scrutiny fear and social interaction anxiety. Behaviour Research and Therapy, 36(4), 455-70. [DOI:10.1016/s0005-7967(97)10031-6]

McFarland, B. R., Shankman, S. A., Tenke, C. E., Bruder, G. E., \& Klein, D. N. (2006). Behavioral activation system deficits predict the six-month course of depression. Journal of Affective Disorders, 91(2-3), 229-34. [DOI:10.1016/j.jad.2006.01.012] [PMID]

McNaughton, N., \& Corr, P. J. (2004). A two-dimensional neuropsychology of defense: Fear/anxiety and defensive distance. Neuroscience \& Biobehavioral Reviews, 28(3), 285-305. [DOI:10.1016/j.neubiorev.2004.03.005] [PMID]

Meyer, B., Johnson, S. L., \& Carver, C. S. (1999). Exploring behavioral activation and inhibition sensitivities among college students at risk for bipolar spectrum symptomatology. Journal of Psychopathology and Behavioral Assessment, 21(4), 275-92. [DOI:10.1023/A:1022119414440] [PMID] [PMCID]

Meyer, B., Johnson, S. L., \& Winters, R. (2001). Responsiveness to threat and incentive in bipolar disorder: Relations of the BIS/BAS scales with symptoms. Journal of Psychopathology and Behavioral Assessment, 23(3), 133-43. [DOI:10.1023/A:1010929402770] [PMID] [PMCID]

Mörtberg, E., Bejerot, S., \& Wistedt, A. A. (2007). Temperament and character dimensions in patients with social phobia: patterns of change following treatments? Psychiatry Research, 152(1), 81-90. [DOI:10.1016/j.psychres.2006.10.003] [PMID]

Mosarezaee, M., Tavoli, A., \& Montazeri, A. (2020). Psychometric properties of the Persian version of social anxiety questionnaire for adults (SAQ-A30). Health and Quality of Life Outcomes, 18(1), 1-7. [DOI:10.1186/s12955-020-01457-2] [PMID] [PMCID]

Naeinian, M. R., Shaeiri, M. R., Sharif, M., \& Hadian, M. (2011). [To study reliability and validity for a brief measure for assessing Generalized Anxiety Disorder (GAD-7) (Persian)]. Journal of Clinical Psychology \& Personality, 9(1), 41-50. http:/ / cpap.shahed.ac.ir/article_2647.html

Neal, L. B., \& Gable, P. A. (2017). Regulatory control and impulsivity relate to resting frontal activity. Social Cognitive and Affective Neuroscience, 12(9), 1377-83. [DOI:10.1093/scan/ nsx080] [PMID] [PMCID]

Pélissolo, A., Andre, C., Pujol, H., Yao, S., Servant, D., \& Braconnier, A., et al. (2002). Personality dimensions in social phobics with or without depression. Acta Psychiatrica Scandinavica, 105(2), 94-103. [DOI:10.1034/j.1600-0447.2002.01115.x] [PMID]

Pinto-Meza, A., Caseras, X., Soler, J., Puigdemont, D., Pérez, V., \& Torrubia, R. (2006). Behavioural inhibition and behavioural activation systems in current and recovered major depression participants. Personality and Individual Differences, 40(2), 21526. [DOI:10.1016/j.paid.2005.06.021]

Rodebaugh, T. L., Woods, C. M., \& Heimberg, R. G. (2007). The reverse of social anxiety is not always the opposite: The reverse-scored items of the social interaction anxiety scale do not belong. Behavior Therapy, 38(2), 192-206. [DOI:10.1016/j. beth.2006.08.001] [PMID]

Silk, J. S., Davis, S., McMakin, D. L., Dahl, R. E., \& Forbes, E. E. (2012). Why do anxious children become depressed teenagers? The role of social evaluative threat and reward processing. Psychological Medicine, 42(10), 2095-107. [DOI:10.1017/ S0033291712000207] [PMID] [PMCID]

Smits, D. J., \& Boeck, P. (2006). From BIS/BAS to the big five. European Journal of Personality, 20(4), 255-70. [DOI:10.1002/ per.583]

Spitzer, R. L., Kroenke, K., Williams, J. B., \& Löwe, B. (2006) A brief measure for assessing generalized anxiety disorder: The GAD-7. Archives of Internal Medicine, 166(10), 1092-7. [DOI:10.1001/archinte.166.10.1092] [PMID]

Torrubia, R., Avila, C., Moltó, J., \& Caseras, X. (2001). The Sensitivity to Punishment and Sensitivity to Reward Questionnaire (SPSRQ) as a measure of Gray's anxiety and impulsivity dimensions. Personality and Individual Differences, 31(6), 837-62. [DOI:10.1016/S0191-8869(00)00183-5]

Trew, J. (2011). Exploring the roles of approach and avoidance in depression: An integrative model. Clinical Psychology Review, 31(7), 1156-68. [DOI:10.1016/j.cpr.2011.07.007] [PMID]

Trull, T. J., \& Sher, K. J. (1994). Relationship between the fivefactor model of personality and Axis I disorders in a nonclinical sample. Journal of Abnormal Psychology, 103(2), 350-60. [DOI:10.1037/0021-843X.103.2.350] [PMID]

Vervoort, L., Wolters, L. H., Hogendoorn, S. M., de Haan, E. Boer, F., \& Prins, P. J. (2010). Sensitivity of Gray's behavioral inhibition system in clinically anxious and non-anxious children and adolescents. Personality and Individual Differences, 48(5), 629-33. [DOI:10.1016/j.paid.2009.12.021]

Watson, D. (2009). Differentiating the mood and anxiety disorders: A quadripartite model. Annual Review of Clinical Psychology, 5, 221-47. [DOI:10.1146/annurev.clinpsy.032408.153510] [PMID]

Watson, D., Clark, L. A., \& Carey, G. (1988). Positive and negative affectivity and their relation to anxiety and depressive disorders. Journal of Abnormal Psychology, 97(3), 346-53. [DOI:10.1037/0021-843X.97.3.346] [PMID]

Watson, D., Gamez, W., \& Simms, L. J. (2005). Basic dimensions of temperament and their relation to anxiety and depression: A symptom-based perspective. Journal of Research in Personality, 39(1), 46-66. [DOI:10.1016/j.jrp.2004.09.006]

Zinbarg, R. E., \& Yoon, K. L. (2008). RST and clinical disorders: Anxiety and depression. In P. Corr (Ed.), The Reinforcement Sensitivity Theory of Personality (pp. 360-97) Cambridge: Cambridge University Press. [DOI:10.1017/ CBO9780511819384.013] 
This Page Intentionally Left Blank 